\title{
MicroRNA-381 suppresses proliferation and invasion of prostate cancer cells through downregulation of the androgen receptor
}

\author{
XIN RUI, TING-TING GU, HUA-FENG PAN, SI-LIANG SHAO and HONG-XIANG SHAO \\ Department of Urology, HwaMei Hospital, University of Chinese Academy of Sciences \\ (Ningbo No. 2 Hospital), Ningbo, Zhejiang 315010, P.R. China
}

Received May 22, 2018; Accepted April 17, 2019

DOI: $10.3892 / 01.2019 .10471$

\begin{abstract}
Prostate cancer (PCa) is the most frequently diagnosed malignancy in men and its incidence has increased rapidly worldwide. Notably, the molecular mechanisms underlying prostate tumorigenesis have not been fully identified. The levels of microRNA (miR)-381 have been explored in numerous types of malignancy; however, the expression levels and biological function of miR-381 in $\mathrm{PCa}$ remain largely unknown. In the present study, reverse-transcription polymerase chain reaction was used to detect the expression levels of miR-381 in PCa cells and normal prostate epithelial cells. Subsequently, miR-381 antisense oligonucleotides and mimics were transfected into LNCaP PCa cells. Bioinformatics analysis was performed to identify the potential target genes of miR-381. Protein expression analysis, dual-luciferase reporter assay and a rescue assay were used to confirm the target of miR-381. The data suggested that the expression levels of miR-381 were significantly decreased in PCa cells compared with in normal prostatic epithelial cells. Furthermore, transfection of LNCaP cells with miR-381 mimics suppressed their proliferation, migration and invasion. In addition, bioinformatics analysis suggested that the androgen receptor (AR) was a target gene of miR-381. miR-381 suppressed the expression levels of AR by directly binding to its 3'-untranslated region. Furthermore, transfection with an AR plasmid partially attenuated miR-381-induced inhibition of cell proliferation, migration and invasion. The results of the present study suggested that miR-381 may act as a tumor suppressor in PCa by directly targeting the AR.
\end{abstract}

Correspondence to: Dr Hong-Xiang Shao, Department of Urology, HwaMei Hospital, University of Chinese Academy of Sciences (Ningbo No. 2 Hospital), 41 Xibei Street, Haishu, Ningbo, Zhejiang 315010, P.R. China

E-mail: shaohongxiang@163.com

Key words: prostate cancer, microRNA-381, proliferation, invasion, androgen receptor

\section{Introduction}

Prostate cancer $(\mathrm{PCa})$ is the most commonly diagnosed malignancy and the second most lethal cancer in men. In 2016, it was estimated that 180,890 new cases of PCa were diagnosed, leading to 26,120 deaths worldwide (1).

MicroRNAs (miRNAs/miRs) are endogenous non-coding RNAs, 18-22 nucleotides in length, which bind to the 3'-untranslated region (3'UTR) of target genes and regulate translational repression and/or mRNA degradation (2). miRNAs serve important roles in various biological and pathological processes, including cell development, infection, immunity and carcinogenesis $(3,4)$. Numerous studies have demonstrated that miRNAs may function as oncogenes and/or tumor suppressors $(5,6)$, and that their abnormal expression levels are closely associated with the development and progression of various types of cancer (7).

miR-381 serves as a tumor suppressor in several types of cancer, including PCa $(8,9)$, colon cancer $(10)$, hepatocellular carcinoma (11), lung adenocarcinoma (12), gastric cancer (13) and breast cancer (14). It has been reported that miR-381 inhibits cell proliferation, migration and invasion in epithelial ovarian cancer (15); however, Tang et al (16) demonstrated that miR-381 increases the proliferation of glioma cells in vitro and in vivo, and that this action is associated with decreased activation of extracellular signal-regulated kinase and protein kinase B signaling. Moreover, miR-381 sensitizes renal cancer cells to the cytotoxic action of 5-fluorouracil via inhibition of WEE1 G2 checkpoint kinase expression levels and upregulation of cell division cycle 2 in 786-O cells (17). Collectively, these data suggested that miR-381 serves a complex role in tumorigenesis; however, the underlying mechanism by which miR-381 contributes to PCa tumorigenesis has not been fully elucidated.

The present study aimed to investigate the expression pattern and potential biological function of miR-381 in PCa cells. The results may provide novel insights into the molecular mechanism underlying prostate tumorigenesis and may reveal a potential therapeutic strategy for PCa.

\section{Materials and methods}

Cell culture. The PCa cell line LNCaP and the normal prostate epithelial cell line PrEC were purchased from the 
American Type Culture Collection (Manassas, VA, USA). Cells were cultured in Dulbecco's modified Eagle medium (Gibco; Thermo Fisher Scientific, Inc., Waltham, MA, USA) supplemented with $10 \%$ fetal bovine serum (FBS; Gibco; Thermo Fisher Scientific, Inc.) and 1\% penicillin-streptomycin (Gibco; Thermo Fisher Scientific, Inc.) at $37^{\circ} \mathrm{C}$ in a humidified atmosphere containing $5 \% \mathrm{CO}_{2}$.

RNA isolation and reverse-transcription quantitative polymerase chain reaction (RT- $q P C R)$. Total RNA was extracted from the cell lines using TRIzol ${ }^{\circledR}$ (Invitrogen; Thermo Fisher Scientific, Inc.). cDNA was synthesized and amplified using the Transcript First-strand cDNA Synthesis SuperMix (Beijing TransGen Biotech Co., Ltd., Beijing, China) in accordance with the manufacturer's protocol. PCR was performed using a TaqMan Universal PCR Master Mix kit (Applied Biosystems; Thermo Fisher Scientific, Inc.) in an Applied Biosystems 7500 system (Thermo Fisher Scientific, Inc.). Thermocycling conditions were as follows: $95^{\circ} \mathrm{C}$ for $10 \mathrm{~min}$, followed by 40 cycles of $95^{\circ} \mathrm{C}$ for $15 \mathrm{sec}$, and $60^{\circ} \mathrm{C}$ for $1 \mathrm{~min}$. The small nuclear RNA U6 was used as an internal control. The primers used for RT-PCR were as follows: miR-381: 5'-AGTCTATACAAGGGCAAGCTCTC-3' (forward primer) and 5'-ATCCATGACAGATCCCTACCG-3' (reverse primer); U6snRNA: 5'-CGCAAGGAUGACACGCAA AUUCGUGAAGCGUUCCAUAUUUUU-3'. Gene expression was normalized to $\mathrm{U} 6$ and fold changes were estimated using the relative quantification $\left(2^{-\Delta \Delta \mathrm{Cq}}\right)$ method (18). All reactions were performed in triplicate.

Cell transfection. Hsa-miR-381 mimic (Sense: 5'-UAUACA AGGGCAAGCUCUCUGUTT-3'; anti-sense: 5'-ACAGAGAGC UUGCCCUUGUCGCTT-3'), miR-381 antisense (5'-ACAGAG AGCUUGCCCUUGUAUA-3') and miR-381 negative control (5'-AUCAUCUAUACUGUAAGUAC-3') oligonucleotides were chemically synthesized by Shanghai GenePharma Co., Ltd. (Shanghai, China). For transient transfection, $1 \times 10^{5} \mathrm{LNCaP}$ cells were seeded in 6-well plates, cultured to $70-80 \%$ confluence and transfected with Lipofectamine ${ }^{\circledR} 2000$ (Invitrogen; Thermo Fisher Scientific, Inc.), according to the manufacturer's protocol. The final concentration of miR-381 mimic, miR-381 antisense (anti-miR-381) or miR-381 scramble (miR-NC) in the transfection system was $100 \mathrm{nM}$. At $24 \mathrm{~h}$ following transfection, the cells were used for the subsequent experiments.

Cell proliferation. $\mathrm{LNCaP}$ cells proliferation was evaluated using the MTT assay. A total of $5 \times 10^{3} \mathrm{LNCaP}$ cells were seeded into each well of a 96-well plate and incubated for 24,48 or $72 \mathrm{~h}$. Subsequently, $20 \mu 10.5 \mathrm{mg} / \mathrm{ml}$ MTT solution (dissolved in DMSO) was added to each well. Following removal of the medium, the absorbance was measured using a spectrophotometer at a wavelength of $570 \mathrm{~nm}$ (Thermo Fisher Scientific, Inc.).

Cell apoptosis. The induction of apoptosis was measured using flow cytometry. The LNCaP cells were harvested, washed twice with ice-cold PBS, and then resuspended in 1x binding buffer (Invitrogen; Thermo Fisher Scientific, Inc.) at a concentration of $6 \times 10^{5}$ cells $/ \mathrm{ml} .100 \mu \mathrm{l}$ of the solution $\left(6 \times 10^{4}\right.$ cells $)$ was then transferred to a $5 \mathrm{ml}$ culture tube. The cells were then incubated with $5 \mu$ l Annexin V-fluorescein isothiocyanate
(BD Biosciences, San Jose, CA, USA) and $5 \mu 1$ of $1 \mathrm{mg} / \mathrm{ml}$ propidium iodide (PI) at room temperature in the dark for $15 \mathrm{~min}$. Following the incubation period, $400 \mu \mathrm{l}$ of $1 \mathrm{X}$ binding buffer was added to each sample and the samples were analyzed using a FACSCalibur flow cytometer (BD Biosciences, San Jose, CA, USA). The results were obtained by analyzing the data with FlowJo software (version 7.6.1; FlowJo, LLC, Ashland, OR, USA). All assays were repeated three times.

Transwell assay. The migratory and invasive abilities of $\mathrm{LNCaP}$ cells were assayed using Transwell chamber (Corning Inc., Corning, NY, USA). For the migration assays, $1 \times 10^{5}$ cells were plated in the top chamber containing a non-coated membrane. The cells were plated in the serum-free medium and medium (Invitrogen; Thermo Fisher Scientific, Inc.) supplemented with $10 \%$ FBS was used as a chemoattractant in the lower chamber. For invasion assays, the filters were precoated with Matrigel (BD Biosciences) in the upper chamber prior to cell seeding. Subsequently, $2 \times 10^{4}$ cells were seeded into the upper chamber and the lower chamber was filled with culture medium supplemented with $10 \% \mathrm{FBS}$. The cells were incubated at $37^{\circ} \mathrm{C}$ in a tissue culture incubator with $5 \% \mathrm{CO}_{2}$. After $16 \mathrm{~h}$, cells that had migrated and invaded to the lower membrane surface were fixed with $4 \%$ paraformaldehyde (Beijing Solarbio, Science \& Technology Co., Ltd., Beijing, China) for $10 \mathrm{~min}$ and stained with $0.1 \%$ crystal violet for $10 \mathrm{~min}$ at room temperature. Migratory/invasive cells in five random fields were counted using a light microscope (Olympus Soft Imaging Solutions GmbH, Münster, Germany). Three independent experiments were conducted for each assay.

Bioinformatics analysis. Potential target genes of miR-381 were predicted and analyzed using TargetScan 6.2 (www.targetscan. org) and miRanda (http://www.microrna.org/microrna/home. do) $(19,20)$.

Western blot analysis. LNCaP cells were harvested and lysed in radioimmunoprecipitation assay buffer $(150 \mathrm{mM} \mathrm{NaCl}$, $50 \mathrm{mM}$ Tris-HCl, $1 \%$ NP-40; $\mathrm{pH}$ 7.5). The Bradford assay (Bio-Rad Laboratories, Inc., Hercules, CA, USA) was used to determine protein concentration. Equal amounts $(50 \mu \mathrm{g})$ of protein were separated via SDS-PAGE on an $8 \%$ gel and transferred onto a nitrocellulose membrane (EMD Millipore, Billerica, MA, USA). After blocking with $10 \%$ non-fat dry milk in Tris-buffered saline for $1 \mathrm{~h}$ at room temperature, the membranes were incubated overnight with anti-androgen receptor (AR) antibodies (cat. no. sc-7305; dilution, 1:500; Santa Cruz Biotechnology, Inc., Dallas, TX, USA) at $4^{\circ} \mathrm{C}$, followed by horseradish peroxidase-conjugated goat anti-rabbit secondary antibodies (cat. no. 7074; dilution, 1:1,000; Cell Signaling Technology, Inc., Danvers, MA, USA) for $1 \mathrm{~h}$ at room temperature. The signals were detected using the SuperSignal West Pico Chemiluminescent Substrate kit (Pierce; Thermo Fisher Scientific, Inc.) according to the manufacturer's protocol. Protein levels were normalized to total GAPDH, using a monoclonal anti-GAPDH antibody (cat. no. sc-293335; dilution, 1:1,000; Santa Cruz Biotechnology, Inc.).

Dual-luciferase reporter assay. The 3'-untranslated region (3'-UTR) of the AR that was predicted to interact with 

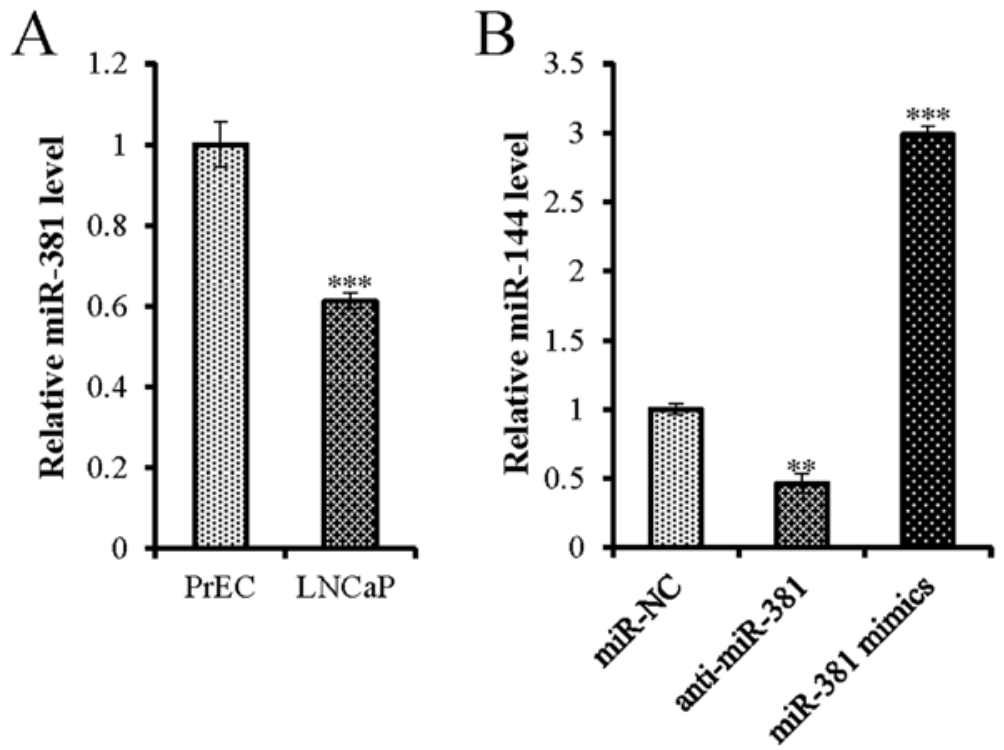

Figure 1. Expression levels of miR-381 in PCa cells. (A) miR-381 expression levels were determined by RT-qPCR in the PCa cell line LNCaP and the normal prostate epithelial cell line PrEC. ${ }^{* * *} \mathrm{P}<0.001$ vs. PrEC (B) RT-qPCR was used to confirm the successful transfection of miR-381 antisense and miR-381 mimics. ${ }^{* *} \mathrm{P}<0.01$ vs. miR-NC group; ${ }^{* * *} \mathrm{P}<0.001$ vs. miR-NC group. miR, microRNA; NC, negative control; PCa, prostate cancer; RT-qPCR, reverse-transcription polymerase chain reaction.

miR-381 was amplified and inserted into pMIR-Report Luciferase vector (Ambion; Thermo Fisher Scientific, Inc.). Mutations within potential miR-381-binding sites were generated by nucleotide replacement. The $20 \mathrm{ng}$ reporter vectors, $1 \mathrm{ng}$ pRL-TK Renilla plasmid (Promega Corporation, Madison, WI, USA) and $20 \mathrm{nM}$ miR-381 mimic or negative control were transiently co-transfected into $1 \times 10^{6}$ cells using Lipofectamine $^{\circledR} 2000$. After $24 \mathrm{~h}$, the activities of firefly luciferase and Renilla luciferase in the cell lysates were measured with the Dual-Luciferase reporter assays (Promega Corporation, Madison, WI, USA), and values for cells with reporter genes containing the wild-type AR 3'-UTR were set equally to 1 . Each experiment was repeated three times.

Co-transfection of cells with miR-381 and AR. AR DNA sequences were amplified from LNCaP cell cDNA by PCR, then subcloned into the pcDNA3.1+ vector (Invitrogen; Thermo Fisher Scientific, Inc.) and verified by DNA sequencing (Shanghai GenePharma Co., Ltd., Shanghai, China). Primers for the amplification were as following: Forward: 5'-AAGCTT TACTCCTCTGCAGTGCCTTG-3'; reverse: 5'-GGATCC ACTGGGCCATATGAGGATCA-3'. miR-381 mimics/mimic control $(50 \mathrm{nM})$ and the pc-AR plasmids $(0.25 \mu \mathrm{g})$ were co-transfected into cultured $1 \times 10^{5} \mathrm{LNCaP}$ cells using Lipofectamine ${ }^{\circledR} 2000$ (Invitrogen; Thermo Fisher Scientific, Inc.) and incubated for $48 \mathrm{~h}$. After $48 \mathrm{~h}$, the cells were used for the subsequent experiments.

Statistical analysis. Data are presented as the mean \pm standard deviation from at least three independent experiments. Statistical analysis was performed by SPSS software (version 13.0; SPSS, Inc., Chicago, IL, USA). Comparisons between two groups were performed using Student's t-test. The differences among three or more groups were compared by one-way analysis of variance followed by the least significant difference post hoc test. $\mathrm{P}<0.05$ was considered to indicate a statistically significant difference.

\section{Results}

Downregulation of miR-381 in PCa cells. To examine the function of miR-381 in the malignant transformation of prostate epithelial cells, its expression levels were analyzed in the $\mathrm{PCa}$ cell line $\mathrm{LNCaP}$ and the normal human prostate epithelial cell line PrEC. The expression levels of miR-381 in LNCaP cells were $\sim 38.83 \%$ lower than those detected in the PrEC cells (Fig. 1A), indicating that miR-381 was downregulated in PCa cells.

miR-381 suppresses the proliferation of PCa cells. To clarify the role of miR-381 in PCa progression, miR-381 antisense oligonucleotides and mimics were transfected into $\mathrm{LNCaP}$ cells. The cells were further assessed in terms of their proliferative and apoptotic activities. Successful transfection of miR-381 antisense oligonucleotides and mimics was confirmed by RT-qPCR (Fig. 1B). Overexpression of miR-381 significantly inhibited cell proliferation (Fig. 2A) and increased apoptosis of LNCaP cells (Fig. 2B and C), whereas the opposite results were observed when miR-381 was silenced. Therefore, these results suggested that overexpression of miR-381 may inhibit $\mathrm{PCa}$ cell proliferation and promote apoptosis in vitro.

miR-381 inhibits migration and invasion of PCa cells. The role of miR-381 in PCa cell migration and invasion was investigated. miR-381 oligonucleotides and mimics were transfected into PCa cells. Overexpression of miR-381 inhibited the migratory and invasive activities of PCa cells compared with the corresponding activities of the cells in the control group (Fig. 2D and E). In addition, with decreasing expression of miR-381, the migration and invasion of PCa cells was attenuated (Fig. 2D and E).

miR-381 directly targets $A R$. The aforementioned results suggested that miR-381 may act as a tumor suppressor in 

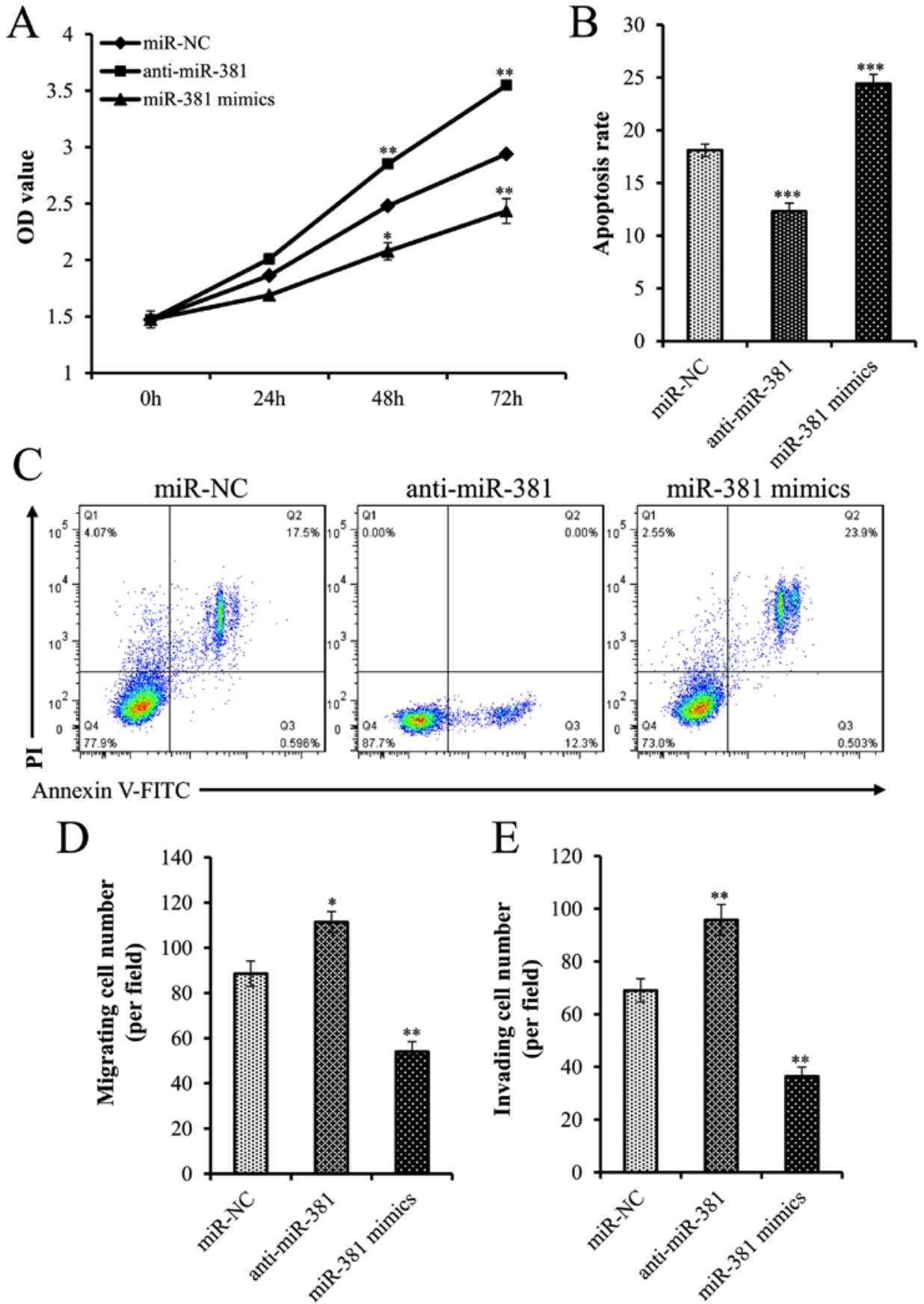

Figure 2. miR-381 suppressed the proliferation, migration and invasion of PCa cells. (A) MTT assay was performed to examine LNCaP cell proliferation. (B and C) Flow cytometry was performed to detect the apoptotic rate of LNCaP cells. (D) Migration assay of LNCaP cells transfected with miR-NC, anti-miR-381 or miR-381 mimics. (E) Invasion assay of LNCaP cells transfected with miR-NC, anti-miR-381 or miR-381 mimics. ${ }^{*} \mathrm{P}<0.05,{ }^{* * *} \mathrm{P}<0.01,{ }^{* * *} \mathrm{P}<0.001$ compared with miR-NC. FITC, fluorescein isothiocyanate; miR, microRNA; NC, negative control; OD, optical density; PI, propidium iodide.

PCa. Consequently, the putative target genes of miR-381 were investigated using TargetScan and miRanda. Excitingly, the results revealed that there were consequential pairs between miR-381 and 3'UTR of AR. A sequence analysis revealed that the putative targeting site of miR-381 was located at nt 1508-1519 of the AR 3'UTR (Fig. 3A), indicating that AR may be a regulatory target of miR-381 and was selected for subsequent investigation (Fig. 3A). Overexpression of miR-381 decreased AR expression levels, whereas inhibition of miR-381 increased the protein expression levels of AR (Fig. 3B), suggesting that the AR was a target gene of miR-381. To further confirm that the AR is a direct target of miR-381, a dual-luciferase reporter assay was performed. Overexpression of miR-381 significantly suppressed the luciferase activity of wild-type AR 3'UTR. This effect was fully reversed when the potential miR-381 binding site was mutated (Fig. 3C).

$A R$ overexpression partially reverses the tumor-suppressive effects of $m i R-381$. To further verify the interaction between miR-381 and the AR, this study investigated whether overexpression of AR rescued PCa cells from the inhibitory effects of miR-381. Successful transfection of an AR plasmid was confirmed by western blot analysis (Fig. 4A). Furthermore, transfection with the AR plasmid reversed the effects 
A

\section{Androgen receptor}

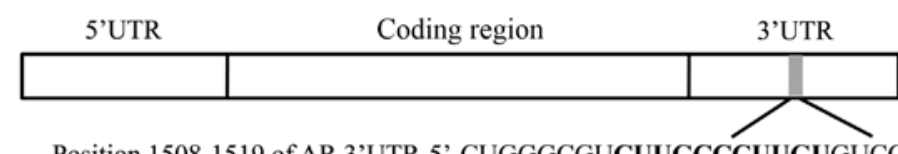

Position 1508-1519 of AR 3'UTR 5'-CUGGGCGUCUUGCCCUUGUGUCCC-3' hsa-miR-381 3'-UGUCUCUCGAACGGGAACAUAU-5

$\mathrm{B}$ AR GAPDH

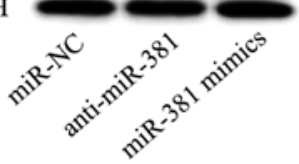

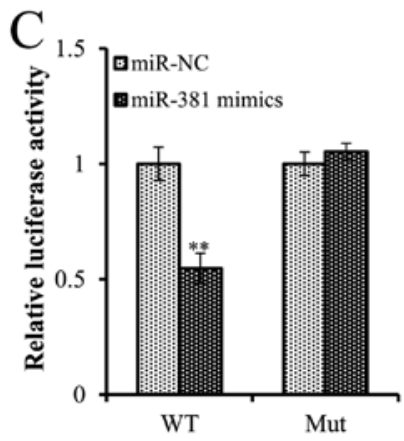

Figure 3. AR is a direct target gene of miR-381. (A) Schematic diagram of a highly conserved miR-381 binding site in the AR 3'UTR. (B) Protein expression levels of AR in LNCaP cells transfected with miR-NC, anti-miR-381 or miR-381 mimics, as determined by western blot analysis. (C) Luciferase activity of the WT and mutant AR 3'UTR co-transfected with miR-NC and miR-381 mimics. ${ }^{* * *} \mathrm{P}<0.01$ compared with miR-NC. AR, androgen receptor; miR, microRNA; mut, mutant; NC, negative control; UTR, untranslated region; WT, wild-type.

A

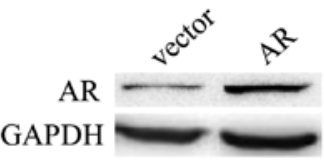

$\mathrm{B}$

$\mathrm{D}$

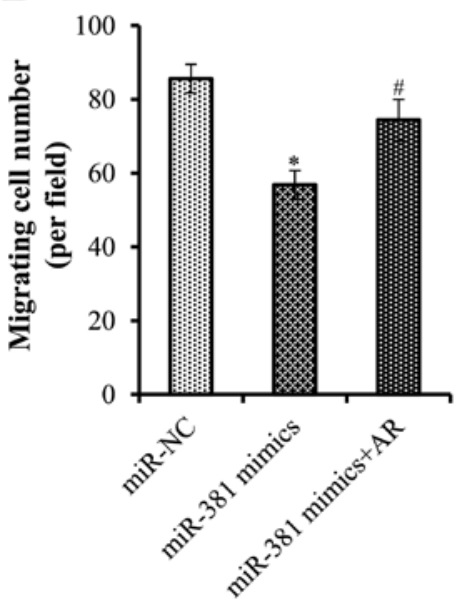

C

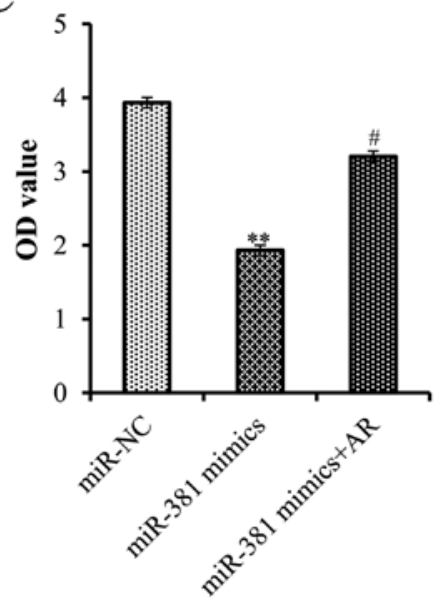

$\mathrm{E}$

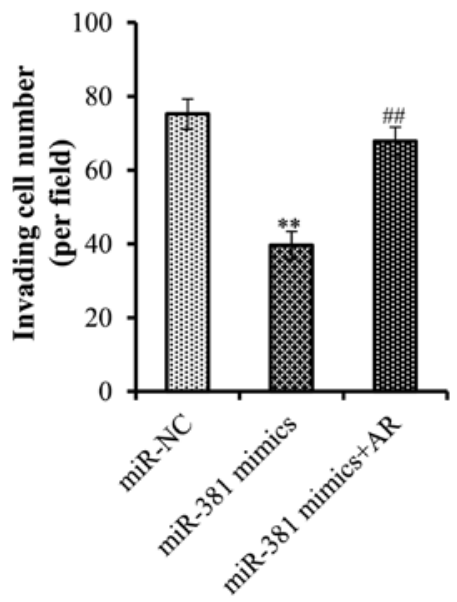

Figure 4. AR overexpression partially reverses the tumor suppressive effects of miR-381. (A) LNCaP cells were transfected with miR-381 mimics with/without AR overexpression plasmid. (B) AR expression was enhanced in cells transfected with miR-381 mimics and AR overexpression plasmid. (C) MTT, (D) migration and (E) invasion assays were performed to measure the proliferation, migration and invasion of LNCaP cells transfected with miR-381 mimics with or without AR. " $\mathrm{P}<0.05,{ }^{* *} \mathrm{P}<0.01$ compared with miR-NC; ${ }^{"} \mathrm{P}<0.05,{ }^{\# \#} \mathrm{P}<0.01$ compared with miR-381 mimics. AR, androgen receptor; miR, microRNA; NC, negative control; OD, optical density. 
of miR-381 overexpression on AR expression (Fig. 4B). Furthermore, overexpression of AR significantly attenuated the tumor suppressive effects of miR-381, highlighting the importance of the AR for the action of miR-381 in cell proliferation, migration and invasion (Fig. 4C-E).

\section{Discussion}

It is well known that a number of miRNAs are involved in prostate tumorigenesis $(21,22)$. In the present study, miR-381 was significantly downregulated in PCa cells compared with in normal prostate epithelial cells. Furthermore, overexpression of miR-381 suppressed the proliferation, migration and invasion of PCa cells, suggesting that miR-381 may serve a role as a potential tumor suppressor in $\mathrm{PCa}$.

miR-381 has attracted attention for its role in carcinogenesis and cancer treatment. Several studies have demonstrated that miR-381 functions as a tumor suppressor, and is able to suppress tumor grow th and progression in colon cancer, ovarian cancer and renal carcinoma $(10,15,23)$. Zhang et al (11) demonstrated that miR-381 may serve as a novel tumor suppressor that decreases hepatocellular carcinoma growth and invasion by targeting liver receptor homolog-1. Xue et al (14) suggested that miR-381 serves a major role in breast cancer growth, epithelial-mesenchymal transition (EMT) and metastasis by targeting $\mathrm{C}-\mathrm{X}-\mathrm{C}$ chemokine receptor 4 . In addition, the restoration of miR-381 significantly inhibits the invasion and migration of colorectal cancer cells and the EMT (24). Conversely, loss of miR-381 expression predicts poor prognosis in lung adenocarcinoma (12). Furthermore, miR-381 is aberrantly downregulated in human myelogenous leukemia (K562/ADM) cells, whereas overexpression of miR-381 is correlated with reduced expression of the multidrug resistance protein 1 and increased drug uptake by cells (25). These findings suggest that miR-381 may target different genes in various cell types, contributing to different biological processes. Notably, it has been reported that the expression levels of miR-381 are reduced in PCa $(8,9)$. Nevertheless, the biological function and the underlying mechanism of miR-381 in PCa remain unclear. The current study identified miR-381 as a potential tumor suppressor in PCa cells.

In order to elucidate the molecular mechanisms involved in miR-381-mediated inhibition of cell proliferation, migration and invasion, the AR was selected for further analysis as it was identified as one the predicted target genes of miR-381. The AR is a steroid hormone-activated transcription factor that belongs to the steroid/nuclear receptor superfamily (26). This receptor controls the growth and differentiation of the normal prostate gland, and serves an important role in the development and progression of castration-resistant PCa (27). Although androgens are the primary ligand for the AR, additional factors such as interleukin-6, transcriptional intermediary factor 2 may contribute to its abnormal activation in their absence $(28,29)$. The AR regulates downstream target genes and alters various cell functions, including cell proliferation, cell cycle progression and apoptosis (30-32). It has been reported that the AR serves a central role in the development and progression of androgen-independent PCa via multiple mechanisms (33). Therefore, it is essential to examine the effective inhibition of the expression and function of the AR, so as to prevent the development of PCa. In the present study, overexpression of miR-381 reduced the expression levels of AR. Bioinformatics analysis revealed binding sites for the miR-381 seed sequence in the 3'UTR of AR. Deletion mutagenesis and a dual-luciferase reporter gene assay demonstrated that the predicted miR-381 target sites in the 3'UTR of AR were functional. Furthermore, the present study indicated that miR-381 effectively decreased the protein expression levels of AR, whereas inhibition of miR-381 revealed opposite results. Finally, overexpression of AR partially reversed miR-381-induced inhibition of $\mathrm{PCa}$ cell proliferation, migration and invasion. Future studies are required to explore other target genes of miR-381 that may be involved in PCa.

In conclusion, the present study highlighted the roles of miR-381 in terms of its ability to suppress growth, migration and invasion of PCa cells by directly targeting the AR. These findings suggested that miR-381 may act as a tumor suppressor in $\mathrm{PCa}$, and may serve as a novel therapeutic target.

\section{Acknowledgements}

The authors would like to thank Dr Huizhi Zhang (Ningbo Diagnostic Pathology Center) for assistance with the Transwell assay.

\section{Funding}

The present work was supported by the Hospital Foundation of the HwaMei hospital, University of Chinese Academy of Sciences (Ningbo No. 2 Hospital) (grant no. 2018HMKY36).

\section{Availability of data and materials}

The datasets used and/or analyzed during the current study are available from the corresponding author on reasonable request.

\section{Authors' contributions}

XR, TTG and HXS conceived the study and revised the manuscript. XR, HFP and SLS wrote the main text and prepared all of the figures. XR performed all the experiments. HXS provided funding support. All authors reviewed the manuscript. All authors read and approved the final manuscript.

\section{Ethics approval and consent to participate}

Not applicable.

\section{Patient consent for publication}

Not applicable.

\section{Competing interests}

The authors declare that they have no competing interests.

\section{References}

1. Siegel RL, Miller KD and Jemal A: Cancer statistics, 2016. CA Cancer J Clin 66: 7-30, 2016. 
2. Bartel DP: MicroRNAs: Genomics, biogenesis, mechanism, and function. Cell 116: 281-297, 2004.

3. He L and Hannon GJ: MicroRNAs: Small RNAs with a big role in gene regulation. Nat Rev Genet 5: 522-531, 2004.

4. Bartel DP: MicroRNAs: Target recognition and regulatory functions. Cell 136: 215-233, 2009.

5. Esquela-Kerscher A and Slack FJ: Oncomirs-microRNAs with a role in cancer. Nat Rev Cancer 6: 259-269, 2006

6. Lu J, Getz G, Miska EA, Alvarez-Saavedra E, Lamb J, Peck D, Sweet-Cordero A, Ebert BL, Mak RH, Ferrando AA, et al MicroRNA expression profiles classify human cancers. Nature 435: 834-838, 2005 .

7. Garzon R, Calin GA and Croce CM: MicroRNAs in cancer. Annu Rev Med 60: 167-179, 2009.

8. He Y, Zhang Q, Jiang R and Li Y: Role and clinical significance of miRNA-381 in prostate cancer. Int $\mathrm{J}$ Clin Exp Med 10 2173-2180, 2017.

9. Formosa A, Markert EK, Lena AM, Italiano D, Finazzi-Agro' E, Levine AJ, B rnardini S, Garabadgiu AV, Melino G and Candi E: MicroRNAs, miR-154, miR-299-5p, miR-376a, miR-376c miR-377, miR-381, miR-487b, miR-485-3p, miR-495 and miR-654-3p, mapped to the $14 q 32.31$ locus, regulate proliferation, apoptosis, migration and invasion in metastatic prostate cancer cells. Oncogene 33: 5173-5182, 2014.

10. Liang Y, Zhao Q, Fan L, Zhang Z, Tan B, Liu Y and Li Y: Down-regulation of MicroRNA-381 promotes cell proliferation and invasion in colon cancer through up-regulation of LRH-1. Biomed Pharmacother 75: 137-141, 2015.

11. Zhang Q, Zhao S, Pang X and Chi B: MicroRNA-381 suppresses cell growth and invasion by targeting the liver receptor homolog-1 in hepatocellular carcinoma. Oncol Rep 35: 1831-1840, 2016.

12. Rothschild SI, Tschan MP, Jaggi R, Fey MF, Gugger M and Gautschi O: MicroRNA-381 represses ID1 and is deregulated in lung adenocarcinoma. J Thorac Oncol 7: 1069-1077, 2012.

13. Cao Q, Liu F, Ji K, Liu N, He Y, Zhang W and Wang L: MicroRNA-381 inhibits the metastasis of gastric cancer by targeting TMEM16A expression. J Exp Clin Cancer Res 36: 29 2017.

14. Xue Y, Xu W, Zhao W, Wang W, Zhang D and Wu P: miR-381 inhibited breast cancer cells proliferation, epithelial-to-mesenchymal transition and metastasis by targeting CXCR4. Biomed Pharmacother 86: 426-433, 2017.

15. Xia B, Li H, Yang S, Liu T and Lou G: miR-381 inhibits epithelial ovarian cancer malignancy via YY1 suppression. Tumor Biol 37: 9157-9167, 2016

16. Tang H, Liu X, Wang Z, She X, Zeng X, Deng M, Liao Q, Guo X, Wang R, Li X, et al: Interaction of hsa-miR-381 and glioma suppressor LRRC4 is involved in glioma growth. Brain Res 1390: 21-32, 2011

17. Chen B, Duan L, Yin G, Tan J and Jiang X: miR-381, a novel intrinsic WEE1 inhibitor, sensitizes renal cancer cells to 5-FU by up-regulation of $\mathrm{Cdc} 2$ activities in 786-O. J Chemother 25 : 229-238, 2013
18. Livak KJ and Schmittgen TD: Analysis of relative gene expression data using real-time quantitative PCR and the 2(-Delta Delta C(T)) method. Methods 25: 402-408, 2001.

19. Lewis BP, Burge CB and Bartel DP: Conserved seed pairing, often flanked by adenosines, indicates that thousands of human genes are microRNA targets. Cell 120: 15-20, 2005.

20. Enright AJ, John B, Gaul U, Tuschl T, Sander C and Marks DS: MicroRNA targets in drosophila. Genome Biol 5: R1, 2003.

21. Porkka KP, Pfeiffer MJ, Waltering KK, Vessella RL, Tammela TL and Visakorpi T: MicroRNA expression profiling in prostate cancer. Cancer Res 67: 6130-6135, 2007.

22. Ozen M, Creighton C, Ozdemir M and Ittmann M: Widespread deregulation of microRNA expression in human prostate cancer. Oncogene 27: 1788-1793, 2008 .

23. Chen B and Liu B: miRNA-381 inhibits the invasion of renal carcinoma and the underlying mechanisms. Zhong Nan Da Xue Xue Bao. Yi Xue Ban 40: 1053-1059, 2015 (In Chinese).

24. He X, Wei Y, Wang Y, Liu L, Wang W and Li N: miR-381 functions as a tumor suppressor in colorectal cancer by targeting Twist1. Onco Targets Ther 9: 1231-1239, 2016.

25. Xu Y, Ohms SJ, Li Z, Wang Q, Gong G, Hu Y, Mao Z, Shannon MF and Fan JY: Changes in the expression of miR-381 and miR-495 are inversely associated with the expression of the MDR1 gene and development of multi-drug resistance. PLoS One 8: e82062, 2013.

26. Heinlein CA and Chang C: Androgen receptor (AR) coregulators: An overview. Endocr Rev 23: 175-200, 2002.

27. Nadiminty N, Tummala R, Lou W, Zhu Y, Zhang J, Chen X, eVere White RW, Kung HJ, Evans CP and Gao AC: MicroRNA let-7c suppresses androgen receptor expression and activity via regulation of Myc expression in prostate cancer cells. J Biol Chem 287: 1527-1537, 2012.

28. Koochekpour S: Androgen receptor signaling and mutations in prostate cancer. Asian J Androl 12: 639-657, 2010.

29. Marques RB, Dits NF, Erkens-Schulze S, van IJcken WF, van Weerden WM and Jenster G: Modulation of androgen receptor signaling in hormonal therapy-resistant prostate cancer cell lines. PLoS One 6: e23144, 2011.

30. Dehm SM and Tindall DJ: Molecular regulation of androgen action in prostate cancer. J Cell Biochem 99: 333-344, 2006.

31. Lin B, Wang J, Hong X, Yan X, Hwang D, Cho JH, Yi D, Utleg AG, Fang X, Schones DE, et al: Integrated expression profiling and ChIP-seq analyses of the growth inhibition response program of the androgen receptor. PLoS One 4: e6589, 2009.

32. Ngan S, Stronach E, Photiou A, Waxman J, Ali S and Buluwela L: Microarray coupled to quantitative RT-PCR analysis of androgen-regulated genes in human $\mathrm{LNCaP}$ prostate cancer cells. Oncogene 28: 2051-2063, 2009.

33. Heinlein CA and Chang C: Androgen receptor in prostate cancer. Endocr Rev 25: 276-308, 2004. 